\title{
A participação do setor privado na gestão do sistema municipal de educação em Teresina-PI: o caso do programa gestão nota 10 do Instituto Ayrton Senna
}

\author{
The Private Sector Participation in Managing of \\ Municipal Education System in Teresina, Pl: The Case of \\ Management Program Ayrton Senna Grade 10
}

\section{Antonio Glauber Alves Oliveira' Liliene Xavier Luz ${ }^{2}$ Cristiane Rêgo dos Anjos ${ }^{3}$ Elionaira Vieira de Sá4}

\begin{abstract}
Resumo
Oartigoanalisaarelaçãoentreopúblicoeoprivado no sistema municipal de educação de Teresina$\mathrm{PI}$, considerando a parceria entre o Instituto Ayrton Senna (IAS) e a Secretaria Municipal de Educação (SEMEC). Para tanto, metodologicamente o trabalho produziu um levantamento de documentos, bem como realizou entrevistas com gestores do sistema e análise dos dados. A investigação compreende o período de 2001 a2007, na perspectiva compreender a trajetória da parceria e suas implicações para a gestão do sistema municipal de ensino. O roteiro do artigo inicia com uma apresentação das questões legais que sustentam as parcerias entre o público e o privado na gestão da educação, passa então a analisar a implantação, regulamentação e expansão da parceria entre o IAS e a SEMEC. Por fim, o trabalho mostra que o cenário de imbricação entre o público e o privado produz uma perspectiva economicista das políticas educacionais, com feição empresarial de compra e venda de serviços, a partir do momento em que a Secretaria abre espaço para que o Instituto administre também suas ações.
\end{abstract}

Palavras-chave: Relações público/privado; Instituto Ayrton Senna; Programa Nota 10.

\begin{abstract}
The article analyzes the relationship between public and private sectors in the municipal education system of Teresina-PI, considering the partnership between the Institute Ayrton Senna (IAS) and Municipal Department of Education (SEMEC). The methodological approach of this work was investigated documents and interviews with system managers and data analysis. The investigation covers the period from 2001 to 2007 , with a view to understand the trajectory of the partnership and its implications for the management of the municipal school system. The script of the paper begins with a presentation of legal issues that support partnerships between public and privateeducational management, then moves on to examine the implementation, regulation and expansion of the partnership between the IAS and SEMEC. Finally, the paper shows that the scenario of connection between public and private produces an economistic perspective of educational policy, with a business face of market issues, since the Education Department gave permission for the Institute administers also its actions.
\end{abstract}

Keywords: Public/private Relations; Ayrton

Senna Institute; Grade 10 Program. 


\section{Introdução}

Este trabalho tem como objetivo analisar a relação público/privado no sistema municipal de educação de Teresina-PI, a partir da parceria entre o Instituto Ayrton Senna (IAS) e a Secretaria Municipal de Educação (SEMEC).

Os procedimentos metodológicos incluem leituras bibliográficas, levantamento de documentos, entrevistas com gestores do sistema e análise dos dados. O período de investigação compreende o ano de 2001 - equivalente ao início da parceria entre o IAS e a SEMEC - até 2007, na perspectiva compreender a trajetória da parceria e suas implicações para a gestão do sistema municipal de ensino.

Nesse texto apresentaremos inicialmente os aspectos legais que dão sustentação às parcerias entre o público e o privado na gestão da educação. Em seguida, versaremos sobre a implantação, regulamentação e expansão da parceria entre o IAS e a SEMEC. Num terceiro momento, trataremos das ações desenvolvidas no âmbito da parceria. Por último, teceremos algumas conclusões que vislumbramos em relação à pesquisa.

\section{Marco jurídico-político da regulamentação das parcerias entre o poder público e a iniciativa privada na educação no contexto das reformas}

O marco jurídico-político de regulamentação das parcerias entre o poder público e a iniciativa privada no contexto das reformas no Brasil e, no qual está inserida a criação do Instituto Ayrton Senna (IAS), encontra-se ancorado no pressuposto da integração entre o Estado e a sociedade civil em diferentes ações das políticas sociais, particularmente das políticas educacionais.

No que se refere à participação das organizações do setor privado na gestão pública, o aperfeiçoamento e ampliação dessa regulamentação se deram nos anos de 1990, mais precisamente a partir da primeira gestão do governo de Fernando Henrique Cardoso, quando da estruturação da reforma do aparelho do Estado e em meio à redefinição do Estado de Direito. Contudo, em um contexto que já vinha se esboçando desde as reivindicações populares pela universalização das políticas públicas no processo de transição política e de elaboração da Constituição de 1988.

AConstituiçãoFederal de 1988 institucionalizou a participação das organizações representativas da sociedade civil na formulação e no controle das políticas em todos os níveis, bem como a coordenação e a execução dos programas nos diferentes entes da federação e nas entidades definidas como beneficentes (Art. 204). Assim como incentivou a participação das organizações sociais por meio do financiamento indireto como, por exemplo, pela via da isenção fiscal mediante a certificação como entidades beneficentes nos conselhos de Assistência Social.

Esta prerrogativa constitucional foi respaldada pela Emenda Constitucional n. ${ }^{\circ}$ 3/1993 que faculta às esferas federal, estadual ou municipal a concessão de subsídios ou isenções relativas a créditos, impostos, taxas, contribuições, anistia de dívidas, redução de base de cálculo, desde que haja lei específica. Já a Lei n. ${ }^{\circ}$ 8.212/1991 isenta as "entidades beneficentes" da contribuição social sobre o superavit financeiro, da contribuição previdenciária patronal do Instituto Nacional de Seguridade Social (INSS) e da Contribuição para o Financiamento da Seguridade Social (Confins).

$\mathrm{Na}$ década de 1990, as iniciativas tomadas no Brasil pelo poder público, no sentido de regulamentar as novas formas de participação do setor privado nas políticas sociais, tiveram à frente o governo de Fernando Collor de Melo. As reformas iniciadas naquele governo foram desenhadas inicialmente no Plano Nacional de Desenvolvimento Econômico (PNDE) e nos sucessivos planos Collor (I e II), embora com pouco sucesso de aprovação no Congresso Nacional, devido tanto às crises de ordem externa como às de ordem interna, estas últimas evidenciadas pelas tensões sociais e pela frágil base político-partidária do poder executivo. Após o impeachment de Collor em 1993, as reformas foram assumidas pelo governo Itamar Franco até as eleições de 1994 que deram assento ao primeiro mandato de Fernando Henrique Cardoso (FHC), a partir de 1995.

Foi o governo de FHC que redefiniu e ampliou o arcabouço jurídico-político-institucional, visando alterações no campo da economia, das políticas sociais e na administração do Estado. O aspecto legal 
tornou-se um imperativo das reformas canalizadas principalmente para ampliação dos mecanismos de descentralização e interlocução entre o poder público e o setor privado na gestão das políticas.

Inicialmente o governo definiu, entre outras diretrizes, essa forma de participação no Plano Diretor de Reforma do Aparelho de Estado (PDRAE), em 1995, tendo como justificativa um diagnóstico que toma como pressuposto a vinculação entre crise fiscal, burocratização do Estado e instabilidade econômica. Nesse sentido, nesse Plano foram definidas algumas estratégias com fins de reformar o Estado, tais como: política de ajuste fiscal, reforma econômica orientada para uma determinada política industrial e tecnológica, com a finalidade de garantir a concorrência interna e a competição internacional, reforma para a previdência social, busca de inovação dos instrumentos de política social e intento de aumentar a capacidade de "governança" nas políticas públicas (PDRAE, 1995).

Na prática, o governo levou a cabo um conjunto de ações direcionadas para a estabilidade da moeda e para a mudança na gestão das políticas sociais, sobretudo no que diz respeito à participação do setor privado nos serviços públicos. Essa reconfiguração jurídico-política pertence por suposto à propriedade "constituída pelas organizações sem fins lucrativos" (PDRAE, 1995, p. 54) ou por entidades beneficentes, terminando por compor o espaço de conciliação público-privado, o que vem sendo denominado de público não-estatal.

Posteriormente ao PDRAE, algumas leis foram sancionadas com o intuito de definição dos atores, dos espaços intermediários de sua atuação e das formas de sua participação nas políticas sociais. A primeira delas foi a Lei do Voluntariado (Lei 9.608), sancionada em 18 de fevereiro de 1998, que dispõe sobre a atividade do serviço voluntário no Brasil. A Lei acabou por reforçar uma prática antiga do voluntariado no Brasil, mas agregando vastos setores de políticas e de instituições públicas contemporâneas.

No mesmo ano, outra Lei foi sancionada pelo governo FHC na perspectiva de consolidação do público não-estatal: a Lei das Organizações Sociais (Lei 9.637), em 15 de maio de 1998, que dispõe sobre a qualificação de entidades como "pessoas jurídicas de direito privado, sem fins lucrativos"
(BRASIL, 1998b, Art. 1. ). Por essa regulamentação, as atividades das organizações podem ser "dirigidas ao ensino, à pesquisa científica, ao desenvolvimento tecnológico, à proteção e preservação do meio ambiente, à cultura e à saúde..." (BRASIL, 1998b, Art. 1. ${ }^{\circ}$ ). A referida Lei dispõe ainda sobre a criação de um Programa Nacional de Publicização e sobre a extinção de órgãos e entidades cujas atividades seriam por suposto absorvidas por organizações sociais. A ênfase dada é no atendimento ao "cidadão-cliente", nos "resultados qualitativos e quantitativos dos prazos pactuados" e no "controle social das ações" (BRASIL, 1998b, Art. 20).

No ano seguinte, em 23 de março de 1999, o governo sancionou a Lei das Organizações da Sociedade Civil de Interesse Público (OSCIPs) (Lei 9.790), que ficou conhecida como Lei do Terceiro Setor, a qual qualifica as pessoas jurídicas de direito privado como "organizações sem fins lucrativos", aptas à "execução das atividades de interesse público" (BRASIL, 1999). Nessa mesma lógica, a Lei institui e disciplina o Termo de Parceria, no sentido de institucionalizar as formas de "cooperação" entre o poder público e as OSCIPs (BRASIL, 1999). Para alguns autores o "Terceiro Setor" é uma categoria que se situa entre o Estado que seria o primeiro setor e o mercado que seria o segundo setor (FERNANDES, 1994). Contudo, tal categorização evidencia uma tentativa de incorporar na esfera pública o universo das organizações sociais que estavam formalmente ou informalmente dentro ou fora das regulamentações do Estado, incluindo ONGs, movimentos sociais, organizações dos segmentos sindicais, dos empresários etc., buscando agrupar os distintos grupos e classes sociais num mesmo universo societário independente das suas formatações políticas.

No aspecto do plano jurídico-político, desde a década de 1990, o poder público vem reestruturando a parceria com a iniciativa privada, dando continuidade a uma das características do Estado brasileiro, em que a subvenção ao setor privado historicamente ocorre de forma indireta, amparada por determinados mecanismos jurídicos que possibilitam, por exemplo, a isenção de impostos, a subvenção de programas e os projetos da iniciativa privada etc. Essa estrutura legal criada no contexto 
das reformas favorece a ampliação da participação das organizações do setor privado na gestão das políticas sociais, contribuindo para institucionalizar e consolidar "novos atores" no governo da educação pública, a exemplo do Instituto Ayrton Senna.

\section{Implantação, regulamentação e expansão da parceria entre o IAS e a SEMEC}

A parceria entre o Instituto Ayrton Senna (IAS) e a Secretaria Municipal de Educação (SEMEC) de Teresina-PI foi firmada no ano de 2001, objetivando a "melhoria dos indicadores educacionais até então vigente". O convênio foi consolidado a partir de um documento que regulamenta a parceria denominado "Instrumento Particular de Parceria" (2001), que dispõe sobre objetivos, metas e obrigações das partes envolvidas. $\mathrm{O}$ aparato legal foi assinado na gestão do Prefeito Firmino Filho e do Secretário de Educação Kleber Montezuma. A princípio o contrato teve vigência de quatro anos. Após o término desse período o contrato vem sendo renovado anualmente, sob o argumento de que "enquanto as partes envolvidas agirem em consonância com as metas propostas o convênio perdurará" (INSTRUMENTO PARTICULAR DE PARCERIA, 2001).

No início da parceria a Secretaria estruturou suas ações com base em programas que objetivavam corrigir a distorção idade-série e a evasão escolar, tendo como foco a gestão das escolas.

Foi nesse contexto que juntamente o IAS e a SEMEC implantaram o Programa Gestão Nota 10 no ano de 2003. O objetivo é desenvolver ações para fortalecer a gestão educacional, no sentido de fazer com que a escola se aproprie da informação que pertence a ela por meio da disseminação de uma sistemática de acompanhamento de toda a equipe escolar em conjunto com a Secretaria, com especial atenção à figura do gestor (IAS, 2009).

Conforme informações obtidas durante a pesquisa, inicialmente o Instituto preocupou-se em apresentar sua sistemática de trabalho aos gestores das escolas, na perspectiva de divulgar e massificar sua cultura de planejamento com rotinas e monitoramento dos dados pedagógicos, administrativos e financeiros. Isto se deu por meio de um curso de formação destinado aos diretores das escolas da rede municipal realizado num período de quinze dias e monitorado por uma instrutora de uma empresa que prestava assessoria para o IAS. Atualmente as formações são realizadas a cada 40 dias e são direcionadas aos diretores das escolas de ensino fundamental e ministradas pela coordenadora do Programa na Secretaria, tendo como instrumento de trabalho o material didático elaborado e enviado pela equipe do Instituto.

A partir de entrevista realizada durante a pesquisa constatamos que no processo de implantação do programa os sujeitos que atuam nas escolas demandaram certa resistência em relação à intervenção do IAS na gestão das escolas. Mas que, com o passar do tempo as resistências foram diluídas, sob o argumento da "eficiência" das ações do Instituto, conforme afirma essa entrevistada:

Em alguns casos houve resistência quanto ao programa, porque junto com a sistemática foi instituída a figura do superintendente escolar coordenada pela gerência do Programa Gestão Nota 10. Algumas escolas o entenderam como alguém que iria vigiar o trabalho desenvolvido, agora os superintendentes são vistos como peça importante para a gestão escolar. Ouvir isto dos diretores para nós representa uma conquista (ENTREVISTADA B).

Esse argumento demonstra o quanto essa nova sistemática de monitoramento vem sendo incorporada pelos sujeitos das escolas e pelos gestores do sistema.

Uma outra justificativa para a adesão ao convênio encontra-se relacionada aos indicadores do ranking implantado nas escolas da rede municipal de ensino:

em 2000, a SEMEC apresentava um quadro nada animador dos principais indicadores que expressavam o ranking das escolas do Ensino Fundamental da Rede Pública Municipal de Teresina. Os números dos indicadores de qualidade das 153 escolas correspondiam respectivamente a 5,8\% de evasão, 44,2\% de distorção idade-série e 3,4\% de taxa de reprovação (SEMEC, 2009, p. 3).

Ou seja, a justificativa ora apresentada tem como base os indicadores de desempenho das escolas municipais até 2000 levantados pela Secretaria, os quais vêm servindo de diagnósticos para fortalecer a parceria, assim como servindo de adesão ao próprio ranking .

Conforme fontes coletadas no sistema, no início da implantação da parceria, a principal dificuldade enfrentada pela Secretaria foi a resistência por parte de toda a comunidade escolar, principalmente 
dos professores, pedagogos e diretores que alegavam que as "tecnologias sociais" (programas) demandavam muito trabalho no que diz respeito ao cumprimento de metas. Segundo o Entrevistado A, com o passar dos anos esses sujeitos foram percebendo o monitoramento como uma coisa positiva. Por outro lado, a adesão à parceria demonstra a fragilidade na forma de resistência, ligada apenas à demanda de trabalho, sem que tenha uma dimensão mais ampla do que seja a adesão a um projeto político e educativo.

\section{Ações desenvolvidas no âmbito da parceria}

Durante esses anos a parceria entre o Instituto Ayrton Senna (IAS) e a Secretaria Municipal de Educação (SEMEC) vem sofrendo algumas modificações. Em 2001 foram implantados os programas de gestão municipal que começou com o "Escola Campeã", o qual, em 2005, foi transformado emRede Vencer. Na opinião de uma das entrevistadas durante a pesquisa, o motivo da mudança dos programas encontra-se vinculada ao sentido da terminologia que os mesmos apresentam.

o Instituto ampliou seu campo de atuação e transformou um projeto que era o Escola Campeã que era tipo um concurso e em 2005 foi transformado em Rede Vencer, uma rede de colaboração onde estamos sempre nos encontrando, os coordenadores dos vários municípios dessa rede de todos os estados do Brasil trocando experiências e não só nos encontros mas por e-mail também. É uma rede de colaboração. A ideia era transformar o que era um prêmio (gerando competição entre as escolas) em uma rede de colaboração, por isso mudou-se do projeto Escola Campeã para Rede Vencer (ENTREVISTADA C).

O "Rede Vencer" atua nas atividades de correção de fluxo e acompanhamento das séries regulares. Para tanto se encontra dividido em três programas: Correção de Fluxo, que foi subdividido em outros dois outros programas: Se Liga e Acelera, cuja finalidade é respectivamente "alfabetizar" e "acelerar" a aprendizagem dos alunos com distorção idade-série; O Gestão Nota 10, com foco na gestão escolar; e o Circuito Campeão, que atua nas séries regulares.

As ações do Programa Gestão Nota 10 são administradas dentro de uma hierarquia assim distribuída: coordenação do programa, superintendência adjunta e superintendência escolar, setoresresponsáveispeloacompanhamento e monitoramento do gestor e demais integrantes das escolas (SEMEC, 2009, p.23).

As ações da coordenação do Programa Gestão Nota 10 (gerência escolar), estão pautadas nos eixos político, gerencial e pedagógico, articulados com base em indicadores e metas. A coordenação do programa possui as seguintes responsabilidades:

- analisar a implementação da política educacional;

- subsidiar as decisões da Secretaria de Educação com os dados relativos à política educacional;

- atuar ativamente nos processos de decisão das metas relativas a cada indicador do sucesso educacional;

- receber e analisar o consolidado dos dados referentes ao funcionamento e autonomia das escolas;

- gerenciar mensalmente o alcance das metas pelas escolas;

- acompanhar o desenvolvimento das ações e analisar os dados consolidados do Programa de forma integrada e articulada com os demais setores/coordenações da Secretaria de Educação;

- apoiar, fortalecer e orientar em serviço os superintendentes escolares para o alcance das metas do seu grupo de escolas, com base nas informações por eles levantadas e na observação direta das escolas;

- rever sistematicamente a aplicabilidade das normas e leis educacionais com vistas à melhoria contínua dos resultados e ao alcance das metas. (SEMEC, 2009)

A equipe responsável para realizar o monitoramento diário das escolas em seus aspectos administrativos e pedagógicos são as superintendentes escolares que, ao todo somam em torno de 21 integrantes, organizadas em núcleos subordinados a uma superintendente adjunta. As superintendentes escolares têm as seguintes responsabilidades:

- estabelecimento de elo entre as escolas e a SEMEC no processo de implementação das ações do Programa;

- acompanhamento nas escolas da implementação das autonomias administrativa, pedagógica e gestão financeira;

- definição, junto com o diretor e sua equipe, no início do ano, das metas da escola, de acordo com as metas definidas pela SEMEC para a Rede de Ensino;

- responsabilizar-se, conjuntamente com o diretor, pelo cumprimento do calendário escolar, pelos resultados e pelo alcance das metas da escola;

- apoio ao diretor na integração e articulação dos projetos desenvolvidos na escola tais como Se Liga, Acelera Brasil, Circuito Campeão e Gestão Nota 10;

- gerenciamento mensal do alcance das metas dos 
grupos de escolas sob sua responsabilidade, por meio das rotinas de sistemática de acompanhamento;

- avaliação do desempenho e fortalecimento da liderança do diretor, capacitando-o em serviço para atuar de forma integrada com a comunidade escolar;

- realização de visitas, quinzenalmente ou semanalmente, utilizando uma pauta pré-estabelecida pela equipe;

- discussão da pauta, juntamente com o diretor e pedagogo, para possíveis intervenções;

- tomadas de providências pelas superintendentesadjuntas, coordenadores do Programa Rede Vencer e gerentes da SEMEC junto aos atores responsáveis (SEMEC, 2009)

As superintendentes escolares portanto visitam as escolas semanalmente ou quinzenalmente, com o propósito de acompanhar e monitorar indicadores como dias letivos, frequência dos professores e dos alunos e percentual de aprovados. Conforme uma das entrevistadas, o desenvolvimento desse trabalho pelas superintendentes traz sempre um retorno à escola de origem, pois

durante as visitações são levantados através de uma pauta os aspectos da gestão pedagógica, financeira e administrativa das escolas. Posteriormente essa pauta é entregue à superintendente adjunta que, por sua vez, tenta mediar alguma ação se preciso com alguma gerência das escolas visitadas, e aquilo que for de uma complexidade maior é trazido diretamente para mim e, se necessário, são tomadas decisões junto ao secretário (ENTREVISTADA B).

Como conota a fala da entrevistada, o principal propósito desse monitoramento é envolver o diretor da escola na rotina diária, tendo em vista o fortalecimento da gestão da escola.

Segundo registros durante a pesquisa, a parceria atua na gestão escolar por meio de formações continuadas para os gestores da escola e do sistema e para os pedagogos. Os pedagogos são incumbidos de fazer com que essa formação chegue ao professor e, em consequência, reflita em suas ações na sala de aula das escolas da rede. No âmbito da Secretaria, o IAS interfere na organização administrativa, pedagógica e nos processos de avaliação, tendo como principal objetivo a "eficiência" dos resultados educacionais.

Pelo desenho do fluxo gerencial do Programa "Rede Vencer" (anexo), percebe-se que os sujeitos envolvidos em todo esse processo são os gestores do sistema e os sujeitos da escola, conforme as seguintes funções: Secretário da Educação,
Coordenador do Rede Vencer, Coordenadores dos Programas Correção de Fluxo, Gestão Nota 10 e Circuito Campeão, Superintendentes Escolares, Diretores, Coordenadores Pedagógicos, Professores e Alunos. Trata-se de uma "rede de colaboração", com foco na "eficiência" da gestão dos serviços educacionais, em que a SEMEC se tornou o eixo intermediário entre as escolas e o IAS. Nessa perspectiva, o acompanhamento e a avaliação tornaram os principais meios de atuação do IAS nas escolas da rede municipal de ensino de Teresina.

Os alunos das escolas da rede municipal como um todo são submetidos a avaliações realizadas pela SEMEC e pelo IAS. Os professores também passam por avaliações de desempenho sob responsabilidade da SEMEC que repassa as informações para o IAS. Para um dos entrevistados durante a pesquisa, a avaliação do IAS é de ordem quantitativa, mas também é qualitativa, "devido o professor, a partir de uma evidência na sala de aula avaliar o alunado" (ENTREVISTADO A). Afirma o entrevistado que

os avaliadores do IAS possivelmente não tenham uma segurança perfeita na informação, mas que ela é prestada pelo professor que está lá atuando com 0 aluno e os procedimentos avaliativos têm como compromisso principal o sucesso do aluno, os mesmos são realizados através de provas elaboradas pelo próprio Instituto (ENTREVISTADO A).

Os resultados obtidos na rede municipal de ensino são reunidos em um relatório e encaminhados ao IAS pelo banco de dados do Sistema de Informação do Instituto Ayrton Senna (SIASI), para que o Instituto possa avaliar e interferir junto à SEMEC. Para a análise das informações coletadas os envolvidos na avaliação levam em consideração as metas previstas, em que o objetivo das análises é identificar os pontos críticos que possam comprometer os resultados e procederem com seus planos de intervenção (SEMEC, 2009, p. 12).

O SIASI é um banco de dados on-line, concebido pelos envolvidos na parceria como ferramenta de gestão. Foi desenvolvido pela empresa Auge Tecnologia e Sistemas (empresa parceira do IAS) para atender todos os municípios que desenvolvem o Programa Rede Vencer por meio de Contrato de Concessão de Uso e Licença de Software e Outras Avenças (SEMEC, 2009, p. 
12 e 13). Especificamente, no caso do Programa Correção de Fluxo, os dados disponíveis no SIASI são avaliados por outra empresa de nome Exclusão, que surgiu a partir da demanda do próprio Instituto e a sua contratação pela SEMEC é sugestão do mesmo. É interessante pontuar que todos os entrevistados convergem com a afirmativa de que a parceria não envolve encargos financeiros para a Secretaria, contudo ainda que os valores sejam modestos, os dados mostram um repasse financeiro para a manutenção do sistema de informação do Instituto, no caso o SIASI.

De maneira geral, para os entrevistados, a parceria não tem gerado desvantagens para a Secretaria, mas, ao contrário, somente vantagens, pois no âmbito do sistema a ação do Instituto tem gerado e contribuído para uma nova dinâmica de trabalho a partir da implantação das "tecnologias sociais" que vêm desencadeando uma "cultura de monitoramento" das atividades desenvolvidas até então não vigentes dentro do sistema (ENTREVISTADOS A, B e C). Dessa forma a parceria visa interferir de forma "qualitativa e eficiente" no processo educativo das redes escolares do sistema municipal de educação de Teresina. Conforme os gestores da SEMEC, um dos diferenciais na parceria é a avaliação e o olhar externo do Instituto, pois, segundo eles, possibilita uma reflexão constante acerca do seu desempenho tendo em vista a qualidade educacional.

O processo de prestação de contas se dá também por meio de uma cadeia hierárquica de informações acerca dos alunos das escolas, que são repassadas do professor para o pedagogo que, por sua vez, preenche um relatório em relação ao desempenho dos professores e, em seguida, transmite à Secretaria em forma de relatório. Esta, posteriormente, direciona os dados ao Sistema Instituto Ayrton Senna de Informação (SIASI). O diretor neste caso preenche um relatório sobre o pedagogo fazendo observações acerca do trabalho do mesmo tendo em vista sua frequência, participaçãonos planejamentos comos professores, desempenho de ações que visam a unidade da escola e apresentação do plano mensal. $\mathrm{Na}$ Secretaria da Educação os superintendentes fazem um relatório sobre o trabalho dos diretores das escolas de sua responsabilidade observando se o gestor é presente, garante o transporte escolar, garante a merenda, se a escola e os arquivos são organizados.

Quanto aos alunos, o que é avaliado é o desempenho escolar. Como incentivo a SEMEC promove diversas formas de premiações. A Secretaria avalia o desempenho dos alunos da educação infantil, do primeiro e segundo ano do ensino fundamental nos anos pares. As séries finais do quinto ao nono ano são acompanhadas pelas avaliações externas nos anos ímpares. O IAS realiza avaliação dos alunos nas escolas duas vezes por ano (maio e setembro) compreendendo do segundo ao quinto ano. Os testes são aplicados e enviados pela SEMEC. A partir da aplicação da avaliação e envio dos resultados para o Instituto é feita a análise pelo IAS e, somente após o resultado final ser divulgado pela Secretaria é que é enviado para as discussões nas escolas. Pela forma como a avaliação é realizada, a Secretaria acredita que avaliando o desempenho do discente está avaliando o desempenho do professor deste aluno.

A partir dos resultados das avaliações as escolas são classificadas em A, B, C, D ou E. As escolas classificadas em $A, B$ e $C$ recebem uma premiação correspondendo respectivamente ao valor de $10.000,5.000$ e 2.500 reais. Aquelas que ficam nas posições D e E não participam da premiação.

Este tipo de ranking substitui um anterior, em que a premiação incidia sobre o salário dos professores e não às escolas. Segundo critérios estabelecidos pela Secretaria, o novo ranking não depende de inscrição, poisasescolassãoclassificadasdeacordo com o desempenho nas avaliações. Os recursos obtidos com as chamadas premiações devem ser gastos com a escola e a mesma deve apresentar à Secretaria um plano de ação descrevendo como os recursos serão utilizados. Além do ranqueamento, a SEMEC possui o concurso chamado Ação Nota 10, um projeto pensado no âmbito da Secretaria. Segundo os gestores da SEMEC esse concurso não faz parte da parceria. Controversamente foi com base no trabalho de rotina do IAS que a SEMEC construiu o Ação Nota 10, a fim de premiar as escolas que conseguem incorporar as "rotinas de monitoramento". O concurso é realizado uma vez por ano e para concorrer a escola deve atender ao seguinte critério: escrever um relato de uma 
experiência de gestão que teve êxito na escola. As realidades dos níveis de ensino são diferentes, por essa razão, a SEMEC determinou categorias de classificação para o processo de seleção: educação infantil, escolas de $1 .^{\circ}$ a $5 .^{\circ}$ ano, escola de $6 .^{\circ}$ a $9 .^{\circ}$ ano e escolas de $1 .^{\circ}$ a $9 .^{\circ}$ ano.

\section{Considerações aproximadas}

Inicialmente é possível identificar que, dada a metodologia empregada pelo programa investigado, há uma aceitação voluntária por parte dos gestores do sistema municipal de educação de Teresina em incorporar a cultura de organização, acompanhamento e avaliação proposta pelo Instituto Ayrton Senna (IAS). Nesse sentido, a justificativa utilizada pelos gestores para a adesão à parceria é a busca da garantia da eficácia do Estado, especificamente na oferta e na gestão educacional. Além de objetivar a eficiência do sistema municipal, a parceria reforça os princípios da gestão privada e a ideia de publicização, por meio da qual a gestão pública vincula-se cada vez mais às políticas sociais de privatização da gestão por meio da terceirização dos serviços públicos.

A gestão de feição privada no âmbito da esfera pública, mais especificamente as influências do IAS no âmbito da SEMEC se faz presente a partir de sua interferência nos processos decisórios estabelecendo, além de outras orientações na gestão, a organização do sistema e das escolas. Pelas informações obtidas durante a pesquisa, não houve sequer discussões nas escolas em relação à implementação da parceria, foi um processo que se deu de forma burocrática, pelo sistema, revelando a negação da perspectiva de gestão pública e democrática.

Portanto, as conclusões aproximadas são de que o cenário de imbricação entre o público e o privado produz uma perspectiva economicista das políticas educacionais, com feição empresarial de compra e venda de serviços, a partir do momento em que a Secretaria abre espaço para que o Instituto administre também suas ações.

\section{Referências Bibliográficas}

BRASIL. Constituição (1988). Constituição da República Federativa do Brasil. Brasília, DF: Senado Federal, 1988.

BRASIL. Lei 8.212, de 24 de julho de 2001. Dispõe sobre a organização da Seguridade Social, institui Plano de Custeio, e dá outras providências. BRASIL. Emenda Constitucional Federal № 3, de 17 de março de1993.

BRASIL. Lei 9.637, de 15 de maio de 1998. Dispõe sobre a qualificação de entidades como organizações sociais, a criação do Programa Nacional de Publicização, a extinção dos órgãos e entidades que menciona e a absorção de suas atividades por organizações sociais, e dá outras providências.

BRASIL. Lei 9.790, de 23 de março de 1999. Dispõe sobre a qualificação de pessoas jurídicas de direito privado, sem fins lucrativos, como Organizações da Sociedade Civil de Interesse Público, institui e disciplina o Termo de Parceria, e dá outras providências.

BRASIL. Lei N. 9.608, de 18 de fevereiro de 1998. Dispõe sobre o serviço voluntário, e dá outras providências.

BRASIL. Plano Diretor da Reforma do Aparelho do Estado. Brasília: Presidência da República, Câmara da Reforma do Estado, Ministério da Administração Federal e Reforma do Estado, novembro, 1995.

FERNANDES, R. C. Privado, porém público: o Terceiro Setor na América Latina. Rio de Janeiro: Relume Dumará, 1994.

INSTITUTO AYRTON SENNA. Disponível em: http://senna.globo.com/institutoayrtonsenna/. Acesso: 15 de junho de 2009.

PMT/SEMEC. Contrato de Gestão. Teresina, 2002.

PMT/SEMEC. Instrumento Particular de Parceria. Teresina, 2001.

SECRETARIA MUNICIPAL DE EDUCAÇÃO E CULTURA. Disponível em: http://www.semec.pi.gov.brl . Acesso: 14 de junho de 2009. 